\title{
RBEP
}

\section{Sujeito, educação e o trabalho com a Língua Portuguesa na escola básica*}

Tânia Guedes Magalhães

Lucia Furtado de Mendonça Cyranka

http://dx.doi.org/10.1590/S2176-6681/304812685

\section{Resumo}

Este trabalho aborda as concepções de sujeito e educação no âmbito do ensino de Língua Portuguesa na educação básica. Retomamos as palavras de Bakhtin (2006), que enfatiza o lugar e a participação do indivíduo no processo de sua constituição como ser social, sujeito às forças exteriores que sobre ele atuam em diferentes níveis e em variadas proporções, capazes de influenciar na sua constituição como membro da comunidade na qual deixa sua marca. Na enunciação, o sujeito está imerso em uma situação social, necessitando, então, adaptar-se ao contexto imediato e aos interlocutores para interagir por meio da linguagem. Nesse sentido, são os gêneros textuais/discursivos que tornam a comunicação humana possível, como formações sócio-históricas firmadas pela interação social. Um ensino que pretende fazer com que o aluno seja capaz de interagir com o outro por meio da oralidade e da escrita deve tomar como objeto tais gêneros para o desenvolvimento da competência discursiva em situações reais. Aí está o verdadeiro sentido de ensinar: fazer com que o aluno seja capaz de interferir na busca de sentidos, tornando-se agente de sua própria história.

Palavras-chave: sujeito; concepção de linguagem; ensino de Língua Portuguesa; gêneros textuais.

\footnotetext{
- Este trabalho foi apresentado oralmente em sessão de discussão entre grupos de pesquisa da Semana de Educação da Faculdade de Educação da Universidade Federal de Juiz de Fora e, por isso, faz menção, em sua introdução, ao Grupo de Pesquisa citado.
} 


\footnotetext{
${ }^{1}$ Esta introdução foi publicada no volume especial "Linguagem na escola” da Revista Educação em Foco (vol. 16); aqui está apresentada com algumas modificações.

${ }^{2}$ Nupel (Núcleo de Pesquisa e Ensino em Linguagem).
}

\section{Abstract \\ Subject, education, and work with the Portuguese Language in basic education}

This study approaches the conceptions of subject and education in relation to Portuguese language teaching in basic education. We revisit Bakhtin (2006), who emphasizes the individual's position and participation in their process of constitution as a social being, subject to external forces that act on them in different levels and in varied proportions. These forces are capable of influencing their constitution as a member of the community in which they leave their mark. In the enunciation, the subject is immersed in a social situation. He/she then needs to adapt himself/herself to the immediate context and to interlocutors, in order to interact via language. In this sense, text/discursive genres - as social-historical formations established by social interaction - are the mechanisms through which communication is made possible. A student-interaction-based instruction through oral and writing skills should take such genres as objects in fostering the development of discourse competence in real situations. There lies the true core of teaching: constructing students' capability of interfering in the pursuit of meanings, which would make them become agents of their own history.

Keywords: subject; language conception; Portuguese teaching; text genres.

\section{Introdução ${ }^{1}$}

O Grupo Fale (Formação de Professores, Alfabetização, Linguagem e Ensino) desenvolve, desde 2004, pesquisas na área de ensino de linguagem. Está alocado no Neel (Núcleo de Educação e Estudos em Linguagens) antigo Nupel $^{2}$-, da Faculdade de Educação da UFJF.

Inicialmente, em função de estudos e discussões sobre as dificuldades enfrentadas atualmente por professores de Língua Portuguesa na escola pública, o grupo foi movido a investigar temas relativos à formação e à atuação dos professores de linguagem do ensino fundamental inicial e final e ensino médio. Diante das críticas e transformações pelas quais o ensino de Língua Portuguesa passou nas últimas três décadas, as pesquisadoras integrantes do grupo empenharam-se em investigar quais seriam as principais lacunas na formação docente e, diante disso, que tipo de atuação poderia ocorrer para mudar essa realidade. Como consequência, o primeiro projeto de pesquisa investigou quais concepções de linguagem os professores adotavam para o trabalho escolar com a língua materna, quais práticas realizavam na escola com a leitura, a escrita, a gramática, a oralidade e os dialetos populares e como realizavam o trabalho com a diversidade na escola. Os resultados revelaram uma amostra de como estava 
o ensino de Língua Portuguesa em Juiz de Fora e como se poderia propor ações para colaborar com a prática de professores. ${ }^{3}$

Daí em diante, movidas por muitas questões oriundas da primeira pesquisa, foram agregadas novas pesquisadoras e iniciadas novas investigações. Concomitante a isso, o grupo começou a desenvolver projetos de extensão e treinamento profissional, além de outras pesquisas financiadas pela UFJF e por agências como a Fundação de Amparo à Pesquisa do Estado de Minas Gerais (Fapemig) e o Conselho Nacional de Desenvolvimento Científico e Tecnológico (CNPq), de forma a colocar em prática as ações que intervêm justamente nas maiores dificuldades da escola pública atual: o desenvolvimento de habilidades de leitura e escrita. Nesse âmbito, atuam bolsistas dos cursos de Letras e Pedagogia, orientados por professores da UFJF, fator que contribui não só para a melhoria na educação, como também para a formação desses alunos de graduação.

Hoje, o grupo conta com sete pesquisadores e quatro colaboradores, sendo sete do quadro da UFJF (Colégio de Aplicação João XXIII e Faculdade de Educação - Faced) e quatro de instituições públicas e particulares de Juiz de Fora e cidades vizinhas.

Os temas mais investigados constituem aqueles referentes ao trabalho escolar com a língua materna. Durante esses nove anos, foram desenvolvidos projetos de pesquisa, extensão e treinamento profissional na área de formação de professores alfabetizadores, leitura e escrita na escola de ensino fundamental e médio, oralidade no ensino de Língua Portuguesa, gêneros textuais/discursivos, dificuldades de aprendizagem no processo de aquisição e desenvolvimento da escrita, desenvolvimento do léxico infantil e sociolinguística na sala de aula. Boa parte dessas ações de treinamento, extensão e pesquisa vem sendo realizada nas escolas das redes de ensino de Juiz de Fora.

Como se vê, esse grupo se forma como um todo que tenta contribuir, na sua abrangência temática, para uma melhoria do trabalho com a linguagem, leitura, escrita e literatura, na tentativa de participar mais ativamente de projetos inseridos na escola, não só na intervenção com alunos mas também na formação continuada de professores.

Na realização de nossos trabalhos, assumimos, como princípio norteador, uma concepção de sujeito e uma concepção de ensino de língua que embasam a reflexão linguística na escola, que apresentaremos neste artigo em duas seções. Na terceira seção, exploramos a importância dos gêneros textuais/discursivos para o ensino e, por fim, fazemos algumas considerações finais.

\section{Concepção de sujeito}

Ponto de partida fundamental para uma reflexão sobre o trabalho escolar com a língua materna, no nosso caso, o português, é a concepção de sujeito aprendente, isto é, o aluno como alvo da ação educativa do professor e da escola. Sobre esse tema, muitas são as escolhas
${ }^{3}$ Parte dessas informações está
publicada em Calderano e Lopes (2006). 
epistemológicas já elaboradas segundo diferentes correntes de teorias filosóficas, psicopedagógicas e sociológicas ao longo da constituição da história da educação no mundo ocidental. Todas as propostas dessa natureza buscam compreender o lugar e a participação do indivíduo no processo de sua constituição como ser social, sujeito às forças exteriores que sobre ele atuam em diferentes níveis e em variadas proporções, capazes de influenciar na sua constituição como membro da comunidade onde atua e na qual deixa sua marca.

Para a proposta de reflexão inspiramo-nos, no presente trabalho, na concepção bakhtiniana de sujeito que se constitui pela linguagem (Bakhtin, 2006) e nas implicações da análise empreendida por Foucault (2004) relativamente à construção do pensamento moderno, denominada microfísica do poder. Bakhtin (2006) assenta na linguagem o princípio da constituição do sujeito, reconhecendo na comunicação verbal o despertar de sua consciência. Sobre isso, ele assim se expressa:

\begin{abstract}
Os indivíduos não recebem a língua pronta para ser usada; eles penetram na corrente da comunicação verbal, ou melhor, somente quando mergulham nessa corrente é que sua consciência desperta e começa a operar. É apenas no processo de aquisição de uma língua estrangeira que a consciência já constituída - graças à língua materna - se confronta com uma língua toda pronta, que só lhe resta assimilar. Os sujeitos não "adquirem" sua língua materna; é nela e por meio dela que ocorre o primeiro despertar da consciência. (Bakhtin, 2006 p. 111).
\end{abstract}

Foucault (2004) acentua, portanto, a impossibilidade de existência da linguagem fora dos contextos sociais imediatos de tal forma que radicaliza a importância da interação na constituição do sujeito ao afirmar: "Não é a atividade mental que organiza a expressão, mas, ao contrário, é a expressão que organiza a atividade mental, que a modela e determina sua orientação" (Foucault, 2004, p. 116).

Para esse filósofo da linguagem, a organização de toda atividade mental do indivíduo se assenta, portanto, no processo de interação social. Nesse caso, mesmo o monólogo, a reflexão interior, só pode ser interpretado como tendo em vista "[...] um auditório social próprio bem estabelecido, em cuja atmosfera se constroem suas deduções interiores, suas motivações, apreciações, etc." (Foucault, 2004, p. 117).

É, pois, esse auditório social que fornece ao indivíduo a atmosfera para a construção de suas motivações, seu impulso interior para a expressão etc. Ele explica ainda:

A palavra é uma espécie de ponte lançada entre mim e os outros. Se ela se apoia sobre mim numa extremidade, na outra apoia-se sobre meu interlocutor. A palavra é o território comum do locutor e do interlocutor. (Foucault, 2004, p. 117).

Isso significa que devemos compreender o silêncio não como ausência de palavra, mas como um episódio de fértil construção de sentido. Bakhtin distingue dois momentos desse processo: atividade mental do 
eu e atividade mental do nós. Quanto mais próxima do polo do eu, mais tendente à autoeliminação é a atividade mental. Ao contrário, a atividade do nós possibilita o crescimento do grau de consciência do sujeito, que é diretamente proporcional à firmeza e estabilidade da orientação social. Ele explica: "Quanto mais forte, mais bem organizada e diferenciada for a coletividade no interior da qual o indivíduo se orienta, mais distinto e complexo será o seu mundo interior" (Foucault, 2004, p. 119).

Está aí colocada, com toda clareza, a necessidade de se investir, quando se trata do processo de educação, no tratamento adequado da linguagem como lugar de constituição do sujeito. Nesse sentido, é fundamental uma reflexão sobre a orientação tradicionalmente dada ao trabalho escolar com a linguagem, seja nas aulas de português, seja nas das outras disciplinas, pois todas a utilizam como ferramenta indispensável na construção do conhecimento, sendo, portanto, a aprendizagem resultante do processo de interação pela linguagem. Sobre essa questão, nos deteremos mais à frente.

Tudo isso nos leva a considerar a relevância do diálogo, da aceitação do outro, da importância devida à democrática atitude de se considerar a palavra do outro como lugar de construção de sentido. Orlandi (1987), estudando as relações do sujeito com as redes de sentido na construção do seu dizer, propõe a possibilidade de existência de três tipos de discurso: o autoritário, o lúdico e o polêmico. Reconhece-se o discurso pedagógico como do tipo autoritário que em nada incorpora a participação do aluno na construção do conhecimento do objeto e que permanece centrado no ponto de vista do professor, na ausência de explicitações necessárias para a apresentação do referente, resultando em simples imposição: é porque é. Parece estar aí compreendida uma questão ideológica de grande importância no mundo moderno, a constituição da chamada sociedade disciplinar, considerada não simplesmente como sinônimo de organização para o trabalho, mas como parte do que Foucault (2004) denomina microfísica do poder. Cyranka (2005), refletindo sobre o mesmo contexto, lembra a pergunta de Foucault a propósito dos métodos disciplinares e dos processos de exame: "Devemos ainda nos admirar que a prisão se pareça com as fábricas, com as escolas, com os quartéis, com os hospitais, e todos se pareçam com as prisões?" (Foucault, 2004, p. 187).

Essa questão implica, sem dúvida, noutra fundamental nas relações escolares, a expressão do poder, presente no discurso pedagógico autoritário ao qual nos referimos anteriormente. Tratando desse tipo de discurso, Cyranka (2005) explica:

Isso porque, ao contrário do que se supõe, produz-se, frequentemente na escola, um discurso cuja fonte de sentido não está no sujeito que o constrói, mas muito longe, noutros dizeres, provindos de outros lugares sociais, lá onde se instala a luta pela manutenção do poder. Essas vozes ressoam no discurso do professor, naquilo que ele diz e faz com seus alunos. Ainda que não se sinta satisfeito com os resultados de sua ação, tanto que promove uma crítica frequentemente lúcida desses resultados, o deslocamento que consegue promover para melhorar o produto de seu 
trabalho é ainda muito pequeno, porque ele está inserido nesse sistema de forças produtoras de sentidos, acima aludido, dos quais dificilmente se dá conta. (Cyranka, 2005, p. 93).

Tal situação resulta no embate entre forças que são, afinal, o espaço da constituição de subjetividades. Nesse sentido, Ferrari (2010, p. 10) lembra: "Para Foucault, o ponto mais intenso da vida está neste encontro entre poder e resistência". E mais à frente: "Poder e resistência fazem parte de um mesmo jogo de constituição das subjetividades e dos sujeitos, estão presentes nos processos de subjetivação" (Ferrari, 2010, p. 10).

Na sala de aula de Língua Portuguesa esses embates são produzidos, frequentemente, pelo distanciamento entre o saber do aluno - como usuário comum de sua língua materna, fonte da constituição de sua identidade, sendo ele, portanto, sujeito constituído na e pela linguagem - e um outro saber linguístico que o professor lhe oferece, distinto do seu próprio. Conseguir transitar por esse território minado por essas diferentes posições geradoras de enfrentamento, mas que podem constituir oportunidade de construção do sujeito, é um desafio.

Examinaremos, a seguir, duas questões que têm sido tratadas a partir das reflexões bakhtinianas e acolhidas pela linguística aplicada ao ensino de línguas nas escolas. Ambas delineiam propostas didáticas que tornam possível transformar o trabalho escolar com a linguagem numa atividade de construção de conhecimento e não de opressão; de libertação e construção de autonomia mais do que de imposição de um saber pouco significativo para quem o recebe.

Na primeira delas, trataremos da concepção de linguagem, procurando evidenciar o quanto os diferentes modos de conceber essa faculdade humana podem determinar práticas escolares equivocadas ou ações formadoras do sujeito; na segunda, desenvolveremos a proposta de adoção do trabalho escolar com a linguagem a partir dos gêneros textuais/discursivos, questão também desenvolvida por Bakhtin, o filósofo da linguagem que influiu decisivamente nos novos rumos da didática de ensino de línguas. Ambos os temas, como se verá, são de fundamental importância no conjunto das ações escolares e devem ser vistos como fundamentais não apenas no desenvolvimento de competências de uso da Língua Portuguesa - e mesmo na aprendizagem de outras disciplinas, sendo, portanto, uma questão interdisciplinar -, mas, sobretudo, no processo de formação do sujeito aprendente e na constituição da sua identidade.

\section{Concepção de linguagem e ensino de Língua Portuguesa (LP)}

Como vimos na primeira parte deste artigo, a linguagem é lugar de constituição do sujeito. Como consequência desse fato, é preciso refletir sobre uma concepção de linguagem que fundamente o ensino de língua na escola e que esteja compatível com a formação de tal sujeito nas sociedades contemporâneas. Trataremos aqui de abordar algumas concepções de 
linguagem, segundo autores que têm contribuído para as pesquisas sobre ensino de língua.

Geraldi (1984), Travaglia (2000) e Koch (2002) abordam as concepções de linguagem aliadas ao ensino de Língua Portuguesa. Os autores apresentam fundamentalmente três concepções de linguagem: a) como expressão do pensamento; b) como instrumento de comunicação; e c) como processo de interação. Essas três concepções estão aliadas a três grandes correntes dos estudos linguísticos do século 20, e em cada uma delas está implícita uma ideologia.

A linguagem como expressão do pensamento está afinada aos ideais da gramática tradicional. Nessa concepção, temos como ideologia a representação do mundo por meio da linguagem, cuja principal função é refletir o pensamento do sujeito, desconsiderando seu meio social. Quando concebemos a linguagem como tal, podemos ser levados a crer que "pessoas que não conseguem se expressar não pensam" (Travaglia, 2000, p. 21). Para Koch (2002), nessa concepção, temos um "sujeito psicológico", individual, visto como um ego que constrói uma representação mental e deseja que esta seja captada pelo interlocutor da maneira como foi mentalizada. Nesse sentido, desconsideram-se as questões sociais.

A segunda concepção (linguagem como ferramenta de comunicação) está relacionada aos estudos estruturalistas e à teoria da comunicação. A língua é considerada como um código (conjunto de signos que se combinam segundo regras) por meio do qual se transmite alguma informação. Relacionando essa concepção ao sujeito, Koch (2002) esclarece que, concebendo a língua apenas como estrutura, temos um sujeito "assujeitado" pelo sistema, no sentido de que ele não é dono de seu discurso e de sua vontade: "sua consciência, quando existe, é produzida de fora e ele pode não saber o que faz e o que diz. Quem fala na verdade é um sujeito anônimo, social" (Koch, 2002, p. 14).

Já na terceira concepção, que está relacionada aos estudos da Linguística da Enunciação, da Pragmática, da Linguística Textual, da Sociolinguística, da Análise do Discurso, entre outras advindas após a década de 1960, é considerada como uma forma de interação: para além de conceber a linguagem como forma abstrata na mente do sujeito, ou como mensagem a ser transmitida por um código a outro sujeito, a linguagem é idealizada como um lugar de interação humana, no qual o sujeito que fala pratica ações, agindo no mundo e interagindo com a sociedade de forma geral via linguagem oral e escrita. Nesse sentido, a linguagem é considerada uma atividade, sendo possível agir pelo discurso com um objetivo específico em determinado contexto. Koch (2002) considera que, nesta concepção, o sujeito é uma entidade psicossocial, evidenciando seu caráter ativo. "E um sujeito social, histórica e ideologicamente situado, que se constitui na interação com o outro. Eu sou na medida em que interajo com o outro" (Bakhtin apud Koch, 2002, p. 15).

Consideramos que a linguagem como forma ou processo de interação é a concepção mais adequada para o ensino de Língua Portuguesa na escola, visto que, a partir dela, dá-se conta de um ensino produtivo de língua 
4 Referimo-nos à pesquisa realizada pelo Grupo Fale, intitulada "Gêneros textuais ensino: entraves e perspectivas".

${ }^{5}$ Quanto às afirmações feitas aqui sobre professores, fazemos referência a entrevistas gravadas recentemente no projeto de pesquisa "Gêneros textuais e ensino: uma pesquisa com professores de língua portuguesa".

${ }^{6} \mathrm{Na}$ pesquisa de Lemos e Mendes (2007), percebemos que os professores escolhem temas para trabalhar textos em sala de aula (como Dia das Mães, Olimpíadas, drogas, sexualidade). Nesse sentido, não escolhem textos para desenvolver a capacidade de argumentar, de narrar etc. materna, que analisa os aspectos discursivos da língua numa perspectiva do uso e da reflexão linguística nos diversos contextos sociais. Assim, conseguiremos atender à perspectiva de sujeito anteriormente apresentada: um sujeito que se constitui pela linguagem numa dada sociedade porque é autor de seu discurso.

Entretanto, ainda hoje, como vemos nas pesquisas recentes ${ }^{4}$, há a adoção de uma concepção inadequada, resultando daí um trabalho quase que exclusivo de metalinguagem, com memorização de regras e domínio da norma padrão, excluindo o desenvolvimento da competência discursiva do falante e a conscientização sobre a legitimidade dos dialetos sociais. Perdura, até hoje, entre grande parte dos professores ${ }^{5}$ de Língua Portuguesa, a ideia de que ensinar português é auxiliar os alunos a decorar regras para passar em concurso público e vestibular. Outros até fazem considerações sobre mudanças que ocorreram nas últimas décadas, evidenciando, principalmente, a existência do trabalho com textos, contudo, ainda se trata de um trabalho intuitivo ${ }^{6}$.

Como consequência da adoção de uma concepção de linguagem como interação, o texto - oral e escrito -, como materialização do discurso de um sujeito situado, torna-se o principal objeto de ensino. Assumir um trabalho contínuo de análise e produção de textos resulta em desenvolvimento de capacidades de linguagem para a efetiva participação social em contextos diversos. O desafio atual no ensino de Língua Portuguesa está em colocar o texto na base do ensino de língua, considerando seus aspectos linguísticos e discursivos, aliando seu estudo às questões de análise gramatical, às relações entre fala e escrita e ao conhecimento das variedades linguísticas e de seus usos sociais.

Como desdobramento da adoção dos gêneros textuais/discursivos como centrais nos programas e currículos de Língua Portuguesa, poderemos, então, refletir sobre um ensino de gramática alicerçado nos usos da língua, ressaltando o lugar da leitura e da escrita no desenvolvimento de competências que atendam a todos os sujeitos. Isso significa ampliar as habilidades que os alunos trazem de seu meio para a escola.

\section{Gêneros textuais/discursivos e ensino de LP}

Para abordar os gêneros do discurso, necessário se faz perpassar alguns conceitos fundamentais à compreensão desse tema. Bakthin (2006), baseado numa visão de língua como interação, afirma que a enunciação é o produto da interação de dois indivíduos socialmente organizados e, mesmo que não haja um interlocutor real, nós criamos um socialmente definido em nossa mente. Portanto, não há interlocutor abstrato. Como consequência, propõe a enunciação dialógica, visto que toda palavra comporta duas faces. Conforme afirmamos na primeira parte deste artigo, a palavra é determinada tanto pelo fato de proceder de alguém como pelo fato de se dirigir para alguém. Constitui, então, o produto da interação do locutor e do ouvinte. A enunciação é dialógica porque toda palavra serve de expressão - um em 
relação ao outro. É por meio dela que um indivíduo se define em relação ao outro, ou seja, em relação à coletividade.

De acordo com o autor, tanto a atividade mental (o conteúdo a exprimir) quanto a objetivação externa (a enunciação) situam-se em território social. E quando a atividade mental se realiza sob a forma de enunciação, submete-se a uma orientação social, uma vez que se adapta ao contexto social imediato do ato de fala e aos interlocutores concretos. Dessa forma, a linguagem nasce no social, depois é internalizada e, consequentemente, expressa socialmente. Como consequência dessa visão de linguagem situada no social, Bakthin teceu importantes considerações sobre gêneros do discurso. Para ele, as esferas de comunicação humana estão sempre relacionadas à utilização da língua, via enunciados concretos. Cada enunciado reflete as condições específicas e as finalidades das esferas de atividade humana.

Gênero do discurso, para Bakhtin, são os tipos relativamente estáveis de enunciados, elaborados por essas esferas de utilização da língua. As esferas de comunicação constituem dois grandes grupos: esferas do cotidiano (familiares, íntimas, comunitárias) e as esferas do sistema ideológico, constituído (da ciência, da arte, da religião, da política, da imprensa etc.), que comportam os discursos. Os gêneros - que são formas cristalizadas historicamente nas práticas sociais - constituem-se por três elementos básicos: conteúdo temático, estilo e construção composicional. A variedade de gêneros é infinita, uma vez que cada esfera comporta um conjunto de gêneros que se expande à medida que tal esfera se complexifica. Na verdade, o que caracteriza o gênero é o uso social que se faz dele: as finalidades das esferas de comunicação determinam os três elementos que o constituem.

Assim, os gêneros, que são modelos e comuns a todos os indivíduos, fazem a mediação entre as práticas sociais e as atividades de linguagem dos indivíduos. Nesse sentido, Bakhtin (2006, p. 124) afirma que o estudo da linguagem deve ficar em torno das formas e dos tipos de interação verbal em ligação com as condições concretas em que se realiza.

Se, de acordo com Bakhtin, são os gêneros que tornam a comunicação humana possível, concluímos que um ensino que pretenda fazer com que o aluno seja capaz de interagir com o outro por meio da oralidade e da escrita deve tomar como objeto tais gêneros, que permitirão aos alunos ler e ouvir compreendendo, falar e escrever com objetivos definidos em situações comunicativas concretas; ou seja, desenvolver a competência discursiva que será utilizada eficazmente em situações reais.

Nas escolas, é preciso que se conheçam, estudem e apreendam os gêneros, por meios de atividades sistematizadas, já que

quanto melhor dominamos os gêneros, tanto mais livremente os empregamos, tanto mais plena e nitidamente descobrimos neles a nossa individualidade (onde isso é possível e necessário), refletimos de modo mais flexível e sutil a situação singular da comunicação (Bakhtin, 2010, p. 285). 
Nessa direção, importante contribuição diz respeito à proposta de Schneuwly e Dolz (2004), que se preocuparam com a transposição didática dos gêneros, inspirados numa concepção baktiniana de linguagem e vygotskyana de aprendizagem. Para os autores, o ensino de linguagem, priorizando a comunicação dos alunos, deve

\begin{abstract}
prepará-los para dominar a língua em situações variadas; desenvolver nos alunos uma relação com o comportamento discursivo consciente e voluntário, favorecendo estratégias de autorregulação e construir uma representação das atividades escritas e faladas em situações complexas, como produto de um trabalho e de uma lenta elaboração. (Schneuwly; Dolz, 2004, p. 49)
\end{abstract}

Segundo esses autores, "[...] é através dos gêneros que as práticas de linguagem materializam-se nas atividades dos aprendizes" (Schneuwly; Dolz, 2004, p. 52). Desse modo, o desenvolvimento da linguagem se dá por intermédio da exploração das propriedades temáticas, formais e estilísticas comuns e recorrentes nos textos. Incluem-se aí os gêneros orais, devendo a escola tratar como objeto de ensino-aprendizagem a fala pública, nas capacidades de escuta e produção de textos orais.

Os gêneros são megainstrumentos, pois funcionam não apenas como textos que circulam socialmente, mas também como objeto de ensino. Assim, afirmam que a apropriação, pelos alunos, das diferentes dimensões da linguagem ocorre por meio das sequências didáticas (SD) nas práticas escolares. As SD são um conjunto de atividades organizadas sistematicamente em torno de um gênero, planejadas para ensinar um conteúdo específico. Cada etapa permite ao aluno dominar práticas de linguagem tipificadas, cujas características se dão a partir de um modelo didático do gênero escolhido para abordar em sala. As SD conferem ao ensino um caráter organizador, uma vez que permitem ao professor acompanhar e orientar o aluno a ler, escrever, falar e ouvir, explorando as características linguísticas e discursivas dos diversos gêneros estudados.

Consoante Pasquier e Dolz (1996), devemos adotar uma diversidade de textos no estudo sistemático dos gêneros via SD, uma vez que eles são formados por características linguísticas bem precisas e diversas. Ou seja, no desenvolvimento de competências de uso da língua, os textos apresentam-se compostos por sequências tipológicas narrativas, argumentativas, descritivas, instrucionais etc. e, por isso, devemos ensinálas com estratégias de ensino diferenciadas, considerando seus contextos de circulação social. Sendo assim, devem ser relacionados aos textos conteúdos gramaticais/discursivos próprios de tais sequências (como os tempos verbais, os conectores, a paragrafação etc., que são peculiares a cada tipologia).

Outro aspecto importante ressaltado por Pasquier e Dolz (1996) diz respeito à utilização de textos reais ${ }^{7}$, ou seja, textos autênticos que circulam fora da escola, retirados de jornais, revistas, blogs e outros suportes, em vez de trechos adaptados nos livros didáticos ou textos artificiais criados com a função didática de ensinar a ler e a escrever. Dessa forma, conseguiremos 
fazer com que os alunos compreendam o contexto discursivo, tanto para a recepção quanto para a produção oral e escrita, porquanto considerar as características discursivas (interlocutores, contexto de circulação, objetivo comunicativo) é fundamental para os aprendizes adequarem seus textos às situações em que são colocados para interagir por meio da linguagem.

A partir da publicação dos PCN na década de 1980 - e na década seguinte até a atualidade, com a intensa produção de currículos e programas pelas secretarias de educação municipais e estaduais - uma dúvida permeou os meios escolares e acadêmicos: que gêneros eleger para o ensino? Quanto a isso, Marcuschi (2008) esclarece que

é de se indagar se há gêneros textuais ideais para o ensino de língua. Tudo indica que a resposta seja não. Mas é provável que se possam identificar gêneros com dificuldades progressivas, do nível menos formal ao mais formal, do mais privado ao mais público e assim por diante. (Marcuschi 2008, p. 207)

Mais uma vez, é preciso afirmar que devemos escolher aqueles textos que circulam socialmente, que sejam relevantes para determinada comunidade e, principalmente, que façam com que os alunos avancem progressivamente na capacidade de argumentar, de narrar, de descrever etc., de sorte que, ao longo da escolarização, não se deve abordar apenas um gênero e uma tipologia, mas uma diversidade. As características das sequências tipológicas abordadas serão, durante os anos seguintes, retomadas, consolidadas e aperfeiçoadas, de modo que o aluno apreenda as diversas dimensões textuais estudadas, percorrendo das estruturas mais simples às mais complexas.

\section{Considerações finais}

As reflexões até aqui apresentadas apontam, como se vê, para a necessidade de o professor e os agentes escolares, em geral, trabalharem de forma a levar os alunos a se reconhecerem como sujeitos aprendentes, no que se refere ao objetivo de levá-los a desenvolverem sua competência de uso da Língua Portuguesa. Nesse sentido, agem a partir do conhecimento que já possuem e que vão desenvolvendo, sob a orientação do professor e da escola, enquanto atuam na sociedade, nos seus grupos de relacionamento. Seu universo se amplia pouco a pouco, mas é com as informações que vão adquirindo nas interações, dentro e fora da escola, que eles interiorizam, cada vez mais, a língua como objeto de construção da sua subjetividade.

Paulo Freire (1992), tratando da questão relativa ao processo de alfabetização, afirma que o que se pretende é

[...] estimular a capacidade crítica dos alfabetizandos enquanto sujeitos do conhecimento, desafiados pelo objeto a ser conhecido. E exatamente a experiência sistemática desta relação que é importante. A relação do sujeito que procura conhecer com o objeto a ser conhecido. Relação 
que inexiste toda vez que, na prática, o alfabetizando é tomado como paciente do processo, puro recipiente da palavra do alfabetizador. Neste caso, então, não diz a sua palavra. (Freire, 1992, p. 44).

Como se vê, o que esse eminente pedagogo reivindica aqui é a necessidade de a escola preservar, no aluno, sua autonomia e sua capacidade de se reconhecer no objeto de ensino. O trabalho escolar de desenvolvimento de competências de uso da língua, tanto na modalidade oral quanto na escrita, a partir da concepção da linguagem como interação, possibilita que o aluno aprenda sem se sentir pressionado. Nesse caso, ampliar competências constitui libertação, não opressão. O erro, nesse caso, não é objeto de punição, mas oportunidade de refletir e avançar.

O trabalho com os gêneros textuais/discursivos, por outro lado, como se viu, constitui uma demonstração de que a escola e o professor compreendem não ser possível levar o aluno a construir sua identidade sem que ele seja capaz de agir pela linguagem nas diferentes instâncias sociais que a vida lhe exigir. Dominar um gênero significa ser capaz de atuar mais livremente no processo de interação social que o requer como instrumento de ação sobre a realidade.

Reconhecemos aí o verdadeiro sentido de ensinar: fazer com que o aluno seja capaz de interferir na busca de outros sentidos em relação ao que ficou tradicionalmente determinado e, dessa forma, se tornar agente de sua própria história. Significa deslocar-se de sua posição tradicional de aluno-ouvinte para a de aluno-autor, construtor de sua identidade.

O trabalho com a Língua Portuguesa na escola, infelizmente, tem ainda se ressentido da ausência dessas reflexões. Nossas ações, por isso mesmo, têm sido direcionadas para que essas e outras propostas do mesmo teor passem a ser incorporadas ao discurso e à prática pedagógica. Caminhando nessa direção, estaremos trabalhando para desvincular da escola a imagem de instituição opressora, de produção em série, castradora, acolhedora de patologias, e transformá-la no lugar de libertação, de construção da autonomia, de formação do sujeito capaz de construir sua felicidade e colaborar para tornar feliz a sociedade que o acolhe.

\section{Referências bibliográficas}

BRASIL. Ministério da Educação (MEC). Secretaria de Educação Fundamental (SEF). Parâmetros curriculares nacionais: terceiro e quarto ciclos do ensino fundamental: língua portuguesa. Brasília: MEC/SEF, 1998. $106 \mathrm{p}$.

BAKHTIN, M. Marxismo e filosofia da linguagem. 12. ed. São Paulo: Hucitec, 2006.

BAKHTIN, M. Estética da criação verbal. São Paulo: Martins Fontes, 2010. 
CALDERANO, M. A.; LOPES, P. R. C. (Org.). Formação de professores no mundo contemporâneo: desafios, experiências e perspectivas. Juiz de Fora: EDUFJF, 2006.

CYRANKA, L. F. M. O discurso do professor: exercício do poder? Duc in altum, Muriaé, v. 5, n. 1, p. 93-113, 2005.

CYRANKA, L. F.; SCAFUTTO, M. L.; MAGALHÃES, T. G. Variação, gramática, oralidade: contribuições da linguística para a prática do professor de português. In: CALDERANO, Maria da Assunção; LOPES, P. R. C. Formação de professores no mundo contemporâneo: desafios, experiências e perspectivas. Juiz de Fora: Ed. UFJF, 2006.

FERRARI, A. Apresentação: sujeitos, subjetividades e educação. In: FERRARI, A(Org.). Sujeitos, subjetividades e educação. Juiz de Fora: Ed. UFJF, p. 7-18, 2010.

FREIRE, P. A importância do ato de ler: em três artigos que se completam. 27. ed. São Paulo: Cortez, 1992.

FOUCAULT, M. Vigiar e punir. Tradução Raquel Ramalhete. 28. ed. Petrópolis: Vozes, 2004.

GERALDI, J. V. O texto na sala de aula: leitura e produção. 2. ed. Cascavel: Assoeste, 1984.

KOCH, I. V. Desvendando os segredos do texto. São Paulo: Contexto: 2002.

LEMOS, A. C.; MENDES, S. D. Gêneros textuais: reflexões e ensino. In: CONGRESSO DE LETRAS DO CES/JF , 1., 2007. Juiz de Fora. Anais... Juiz de Fora: UFJF, 2007. 1 CD-ROM.

MARCUSCHI, L. A. Produção textual, análise de gêneros e compreensão. 2. ed. Rio de Janeiro: Parábola, 2008.

ORLANDI, E. P. A linguagem e seu funcionamento: as formas do discurso. 2. ed. Campinas: Pontes, 1987.

PASQUIER, A.; DOLZ, J. Un decálogo para enseñar a escribir. Cultura y educación: revista de teoría, investigación y práctica, Logroño, n. 2, p. 31-41, 1996.

SCHNEUWLY, B. e DOLZ, J. Gêneros orais e escritos na escola. Tradução e organização: Roxane Rojo. Campinas: Mercado de Letras, 2004.

TRAVAGLIA, L. C. Gramática e interação: uma proposta para o ensino de gramática no $1^{\circ}$ e $2^{\circ}$ graus. 5. ed. São Paulo: Cortez, 2000. 
Tânia Guedes Magalhães, doutora em Letras - Estudos Linguísticos pela Universidade Federal Fluminense (UFF), é professora da Universidade Federal de Juiz de Fora (UFJF), integrante do Grupo de Pesquisa Fale Formação de Professores, Alfabetização, Linguagem e Ensino, Juiz de Fora, Minas Gerais, Brasil.

tania.magalhaes@ufjf.edu.br

Lucia Furtado de Mendonça Cyranka, doutora em Letras pela Universidade Federal Fluminense (UFF), é professora do Departamento de Educação da Universidade Federal de Juiz de Fora (UFJF), Juiz de Fora, Minas Gerais, Brasil.

Recebido em 2 de agosto de 2013.

Revisado em 20 de janeiro de 2014.

Aprovado em 3 de setembro de 2014. 